\title{
INTER(AÇÃO) SOCIAL NOS CONTEXTOS DE PESQUISA/INTERVENÇÃO EM ESCOLAS DE FORTALEZA ${ }^{1}$
}

\author{
Veriana de Fátima Rodrigues Colaço * \\ Hamilton Viana Chaves" \\ Ana Cleide Barros Jucá \\ Paulo André Sousa Teixeira ${ }^{\infty}$ \\ Ricardo Rilton Nogueira Alves ${ }^{x}$ \\ Ticiana Santiago de Sá
}

\begin{abstract}
RESUMO. Este artigo apresenta a segunda etapa de uma pesquisa que visou a investigar as estratégias de mediação realizadas por crianças em situações de interação no contexto de sala de aula. Também intentou envolver os professores, através de colaboração e intervenção. $\mathrm{O}$ estudo, de base etnográfica, foi desenvolvido em duas escolas do município de Fortaleza, das quais uma era particular e outra, filantrópica. Os procedimentos envolveram observações e vedeogravações das atividades discursivas das crianças no cotidiano de sala de aula quando realizavam conjuntamente tarefas escolares, para posterior análise microgenética. Ao tentar resolver as atividades escolares, as crianças expressavam seus pensamentos, reorganizavam suas ações e buscavam modos viáveis e eficientes para solucionar os problemas. Foram percebidas as peculiaridades de entonação e expressão da linguagem, bem como formas de liderança e modos de legitimação da posição enunciativa de cada criança que reafirmam os processos subjetivos em curso no espaço interativo da sala de aula.
\end{abstract}

Palavras-chave: Interação; mediação semiótica; aprendizagem.

\section{SOCIAL INTERACTION IN THE CONTEXT OF INTERVENTION RESEARCH IN FORTALEZA'S SCHOOLS}

\begin{abstract}
This article presents the second part of a research that aimed to investigate the mediation strategies carried out by children in interaction situations occurred on classroom context. Also, intended to involve teachers by collaboration and intervention. The research, on an ethnographic basis, was developed in two schools of the municipality of Fortaleza: a private one, and another that is philantropical. The proceedings involved observations and tape recordings of the discursive activities of the children in the everyday classroom context while carrying out together the school activities, for further microgenetic analisis. Trying to solve the school activities, children expressed their thoughts, reorganized their actions and searched for new feasible and efficient ways to solve the problems. The particular characteristics of intonations and language expressions were noticed, also as leadership expressions and ways to confirm the enunciative position of each child, which reaffirm the subjective processes occurring in the interactive space of the classroom.
\end{abstract}

Key words: Interaction; semiotic mediation; learning process.

\section{INTERACCIÓN SOCIAL EN LOS CONTEXTOS DE INVESTIGACIÓN/INTERVENCIÓN EN ESCUELAS DE FORTALEZA}

RESUMEN. El siguiente artículo presenta la segunda etapa de una investigación que tuvo como objetivo estudiar las estrategias de mediación realizadas por niños y niñas en situaciones de interacción en el contexto del aula. También hubo un

\footnotetext{
1 Apoio: CNPq e FUNCAP.

Doutora em Educação. Professora do Programa de Pós-Graduação em Psicologia da UFC.

\# Doutorando do Programa de Pós-Graduação em Educação da UFC e Psicólogo do IFET/CE.

^ Mestranda do Programa de Pós-Graduação em Psicologia da UFPE.

æ Psicólogo do Tribunal de Justiça de Pernambuco. Especialista em intervenções psicológicas na infância e adolescência pela FAFIRE.

Ф Mestranda do Programa de Pós-Graduação em Psicologia da UFC.
} 
intento de integrar a los maestros, a través de colaboración e intervención. El estudio, con una base etnográfica, fue desarrollado en dos escuelas de la ciudad de Fortaleza, siendo una de ellas privada y otra filantrópica. Entre los procedimientos están observaciones y grabaciones de video de las actividades discursivas de los niños y niñas en el cotidiano del aula, mientras realizaban en conjunto tareas escolares, para el posterior análisis micro genético. Al intentar solucionar las actividades de la escuela, los niños y niñas expresaban sus pensamientos, reorganizaban sus acciones y buscaban modos viables y eficientes para solucionar los problemas. Se ha percibido las peculiaridades de las entonaciones y expresiones del lenguaje, igualmente que las formas de lideranza y modos de legitimación de la posición enunciativa de cada niño o niña, reafirmando los procesos subjetivos en el espacio interactivo del aula.

Palabras-clave: Interacción; mediación semiótica; aprendizaje.

A escola, embora ainda constitua espaço privilegiado destinado à educação sistemática e continuada para crianças e jovens, não é o único lugar que promove situações educativas formais. Muitos outros ambientes assumem hoje este papel, tanto formal como informalmente. De modo assistemático, aparecem os meios de comunicação de massa, particularmente a televisão e, com uma atuação cada vez mais incisiva, a Internet, principal canal tecnológico de informação e comunicação, que possibilita a interação em sistema de rede mundial e, neste sentido, é um dos artefatos de maior potência como agente educativo do novo milênio.

Neste contexto de condições de intercâmbio globalizado, os níveis de interação social que crianças e jovens de hoje estabelecem ganham dimensões incomensuráveis e podem gerar as mais diversificadas situações de aprendizagem.

Assim, estudar as interações sociais que acontecem entre crianças no espaço de sala de aula, ou seja, as interações face a face que ocorrem num contexto específico, pode parecer um retrocesso, porém ganha sentido quando se trata de compreender o papel funcional e microdimensional que essas interações cotidianas possibilitam no plano do desenvolvimento microgenético da criança. Para isso, considera-se tanto o aspecto cognitivo implicado quanto a construção subjetiva que ocorre nessas interações. Ademais, os padrões de interação que são construídos nos ambientes microrrelacionais refletem, por um lado, modelos aprendidos pelas crianças a partir de sua inserção cultural e, por outro, são reconstruções que elas realizam nas suas experiências específicas, o que, por sua vez, repercute nos níveis mais abrangentes de interação, como no caso das interações em rede.

Sem perder de vista essas considerações acerca de situações de relações sociais mais abrangentes que ocorrem no cotidiano atual, estamos interessados em compreender os significados e sentidos construídos pelas crianças no ambiente escolar, o qual se destina explícita e intencionalmente a promover aprendizagens. Tais aprendizagens não ocorrem unicamente nas interações estabelecidas entre professores e alunos, mas também são possibilitadas pelos modos ou estratégias criados pelos próprios aprendizes ao compartirem a realização de tarefas e solucionarem problemas na sala de aula. Neste sentido, o objetivo central do nosso estudo foi analisar as estratégias de mediação utilizadas pelas crianças em interação no contexto escolar e sua implicação na construção de conhecimento e de subjetividade. Por estratégia de mediação compreendemos o modo como as pessoas utilizam meios (instrumentais ou simbólicos) para intermediar suas atividades, as quais envolvem interação com o outro e o mundo.

Vygotsky (1995) afirma que o desenvolvimento é uma construção social forjada dialeticamente nos planos inter e intramental. Tal pensamento significa que ele (o desenvolvimento) é um processo individual gestado socialmente e mediado pelos diversos contextos em que as pessoas estão inseridas e ferramentas culturais a que têm acesso no curso da vida. Com tal perspectiva, as investigações que realizamos até o momento focalizam as interações entre crianças no contexto da sala de aula. Ao mesmo tempo em que evidencia seus limites, um estudo com tal especificidade também pode trazer contribuições para se compreenderem processos de que uma análise macrossocial das diferentes relações vivenciadas por crianças e jovens pode não dar conta.

Embora os aportes teóricos selecionados por nós, entre os quais a psicologia histórico-cultural, compreendam que a aprendizagem humana começa muito antes do circuito formal de educação, elegemos como foco de pesquisa a forma de aprendizagem constituída nesse contexto. A escola pode ser vista como um espaço singular no favorecimento da construção de conceitos científicos que, segundo Vygotsky (1993), amparam-se e organizam-se a partir dos conceitos cotidianos das crianças.

Quando as crianças atuam coletivamente na realização de tarefas escolares, circulam entre elas significados diversificados, de tal modo que as trocas 
semânticas ganham novos significados e sentidos ${ }^{2}$, sendo amparadas por possíveis conceitos espontâneos pertencentes aos seus repertórios.

A partir dessa ideia buscamos a visão de Bakhtin (1988) como subsídio para melhor compreender a questão. Ele afirma que não há signo vazio, que todo signo é ideológico e dialógico, ou seja, parte de alguém e se dirige a outrem. Por sua vez, em consequência da interação verbal, o autor identifica dois polos nesta relação: um como pertencente a uma atividade mental do eu, que tenderia a se dilapidar, e o outro como a atividade mental do nós. É neste segundo polo que os sentidos são efetivamente compartilhados e alterados em função da ação coletiva de vozes.

Isso torna claros os subsídios teóricos em que nos ancoramos para realizar nossas análises acerca dos diálogos infantis selecionados no corpus da pesquisa. Explicitamos que o propósito deste texto é apresentar os resultados de um estudo realizado em duas escolas de ensino fundamental da cidade de Fortaleza, o qual se deu ao longo de três anos (2004-2006). Trataremos especificamente da segunda etapa do estudo, feito numa escola filantrópica que apresenta uma metodologia de ensino considerada tradicional; além disso, faremos uma comparação com os resultados da primeira etapa, que aconteceu numa escola particular, com uma proposta pedagógica socioconstrutivista. Os resultados dessa primeira etapa foram publicados no artigo intitulado Estratégias de mediação em situação de interação entre crianças em sala de aula ${ }^{3}$.

$\mathrm{Na}$ segunda fase, a pesquisa envolveu mais diretamente os professores do Ensino Fundamental da escola, que participaram de oficinas ministradas pelos pesquisadores. Tais oficinas tinham como objetivo sensibilizá-los para a importância das atividades compartilhadas entre os alunos em sala de aula, considerando que a maior parte das tarefas por eles propostas para os estudantes eram efetivadas de forma individual, dado o enfoque pedagógico tradicional da escola.

Vale ressaltar que não é apenas a realização de tarefas grupais propriamente ditas que concederá à

2 Diferenciamos significado e sentido tomando por base a compreensão de Vygotsky (1993), em que o significado da palavra refere-se ao que é convencionalmente entendido numa comunidade linguística compartilhada e o seu sentido abrange os processos e experiências particulares que envolvem a construção e o uso polissêmico desse significado convencional.

3 Artigo publicado em 2007 na Revista Estudos de Psicologia de Natal - RN (indicado nas referências bibliográficas deste artigo). atividade seu caráter compartilhado e de promoção de aprendizagem, mas é principalmente a maneira de organizar a tarefa, a importância e o significado dados à participação de cada criança, bem como a possibilidade efetiva de trocas, que favorecerá um contexto propício à aprendizagem compartilhada.

\section{O PROCESSO INVESTIGATIVO}

A proposta metodológica do estudo esteve pautada desde o seu início pela perspectiva da pesquisa sociocultural (Wertsch, 1998), que implica uma preocupação de análise qualitativa dos processos em curso, entendidos nos contextos histórico, social, cultural, institucional e ao mesmo tempo singular em que ocorrem.

Freitas (2003) apresenta algumas características da pesquisa qualitativa de orientação sociocultural, as quais seguimos no decorrer de nossa investigação. A primeira delas se refere à compreensão da fonte dos dados como texto e contexto em que surgem, ou seja, não se trata de fatos isolados, mas de fenômenos emergentes no campo social. A segunda tem relação com o problema de pesquisa. Nas palavras da autora, “(...) não se cria artificialmente uma situação para ser pesquisada, mas vai-se ao encontro da situação no seu acontecer, no seu percurso de desenvolvimento" (Freitas, 2003, p. 27). Neste aspecto, reiteiramos a orientação etnográfica do processo investigativo. Em terceiro lugar, Freitas (2003) enfatiza a compreensão e explicação do fenômeno, afirmando que a investigação, nessa abordagem, busca fazer relações entre o individual e o social dos eventos estudados. A característica seguinte define o pesquisador como ser ativo, que intervém no processo com intenção de transformar o fenômeno em seu desenvolvimento. Por fim, a autora refere-se ao critério de validade da investigação, que não está definido pela precisão, mas sim pela “(...) profundidade da penetração e a participação ativa tanto do investigador quanto do investigado" (Freitas, 2003, p.28).

Neste aspecto, interessamo-nos por realizar uma pesquisa-intervenção, não apenas por entendermos a inserção do pesquisador no campo social como uma situação interventiva, mas pela nossa intenção clara de promover alguma mudança na visão dos professores acerca do papel da interação entre as crianças em sala de aula no processo de aprendizagem. Também buscamos, com as oficinas, contextualizar as atividades e referências teórico-metodológicas da pesquisa.

Para tanto, realizamos cinco oficinas com os professores. O estudo envolveu, de início (final de 2005), todos os professores e coordenadores do 
Ensino Fundamental e da Educação Infantil da escola escolhida - uma escola filantrópica situada na periferia da cidade de Fortaleza. Como a participação dos docentes era voluntária, a frequência variou de 18 a 23 deles em cada encontro/oficina. No primeiro momento, realizamos quatro oficinas pedagógicas com os docentes, nas quais foram utilizados como material ilustrativo dos processos e estratégias de mediação observados nas interações entre crianças em sala de aula um texto de revista (Oliveira, 2005) e um vídeo didático produzido com fins pedagógicos (Oliveira, 1996), recursos a que se associou a discussão desse material e das experiências desenvolvidas pelo nosso grupo de pesquisadores em investigações correlatas realizadas anteriormente (Colaço, 2001; Colaço; Pereira; Chaves; Pereira Neto \& Sá, 2007).

Deste modo, fomentou-se junto aos professores o interesse em disponibilizar suas turmas para as posteriores atividades de observação direta das crianças em sala de aula. Duas professoras e um professor concordaram. A pesquisa seguiu então com a observação e registro, por meio de videogravações, das atividades discursivas - compreendidas como linguagem integrada à ação para a realização da tarefa (Coll \& Onrubia, 1998) - de quatro crianças de uma turma de alfabetização, uma dupla de crianças da quarta série e uma dupla de sexta série. O processo de observação e registro desenvolveu-se no decorrer do mês de fevereiro de 2006. Por questões éticas, as crianças que participaram da pesquisa foram aquelas que aceitaram fazê-lo e cujos pais formalizaram oficialmente o seu consentimento. As filmagens eram realizadas duas vezes por semana por membros da equipe de pesquisa divididos em duplas, cada dupla em uma turma.

Foram observadas as situações cotidianas de interação das crianças em sala de aula, nas quais tanto a organização da equipe de crianças como as tarefas propostas para serem resolvidas de forma compartilhada foram inseridas no contexto da atividade escolar e apresentadas pelo professor ou pelas professoras das respectivas turmas. Destarte toda a turma estava envolvida na tarefa, porém focalizávamos as videogravações e registros na dupla ou quarteto escolhidos em cada sala de aula correspondente. As atividades envolviam diferentes conteúdos, relativos à linguagem e à matemática.

As atividades discursivas das crianças (Coll \& Onrubia, 1998) foram submetidas à análise microgenética (Góes, 2000), em que se consideraram as falas e gesticulações das crianças quando da realização conjunta de tarefas escolares, sendo feitos recortes dos momentos em que evidenciávamos processos de mediação entre as crianças na construção da atividade. Definimos categorias para sistematizar as estratégias de mediação identificadas, a partir da compreensão de que, ao realizarem de forma compartilhada as tarefas escolares, as crianças recorrem a meios que potencializam a sua comunicação com o outro, buscando formas de melhor entendimento e de efetivação das tarefas executadas.

Seguimos os mesmos critérios da pesquisa realizada na escola particular (primeira etapa da pesquisa) e acrescentamos ou renomeamos algumas estratégias que melhor caracterizavam as atividades discursivas das crianças nessa segunda escola. Assim, agrupamos as diferentes estratégias de mediação encontradas nas duas pesquisas em três categorias, a saber: estratégias gerais, estratégias de tarefas de linguagem e estratégias de tarefas de matemática.

Ao final das fases de observação e análise, retornamos à escola para uma nova oficina, que foi desenvolvida mais uma vez com a participação de todos os professores e teve como finalidade apresentar e refletir sobre os resultados da pesquisa, utilizando as filmagens feitas nas turmas da própria escola. Nosso compromisso de possibilitar a discussão e envolvimento dos professores na investigação teria que ser completado com este momento final, em que eles não apenas tiveram conhecimento das análises e resultados por nós indicados, mas também puderam discutir e opinar sobre o processo e com ele se comprometer, influenciando inclusive, com suas apreciações, a retomada das análises que fizemos por ocasião da elaboração do relatório da pesquisa.

A última fase do estudo foi desenvolvida internamente, quando fizemos uma análise comparativa das estratégias de mediação identificadas na escola particular (primeira etapa) e as estratégias identificadas na escola filantrópica (segunda etapa).

\section{AS OFICINAS E SUA RELEVÂNCIA NO CONTEXTO DA PESQUISA}

Nas oficinas pedagógicas, os educadores afirmaram que, em algumas ocasiões, promoviam atividades em grupo com os seus alunos, porém isso ocorria de forma esporádica e eles (os professores e as professoras) pareciam não perceber claramente nesses momentos uma dimensão mediadora de construção compartilhada. Ao mostrarmos as videogravações e discutirmos essa potencialidade na realização conjunta das tarefas pelos alunos, os professores identificavam as situações de aprendizagem, inclusive as estratégias mediadoras nesse processo. 
Desta forma, consideramos que as oficinas realizadas atingiram o objetivo de sensibilizar os professores para a importância da realização de atividades que priorizam a interação e o compartilhamento de tarefas em sala de aula. Isto não implica dizer que eles desconhecessem ou não valorizassem o papel construtivo das interações entre os estudantes, mas sim, que não estavam atentos à sua dimensão pedagógica, no sentido de compreender que a atuação do professor na promoção de situações compartilhadas entre os alunos é decisiva para que elas tenham repercussão na relação ensinoaprendizagem que acontece na educação escolar.

Entendemos, ainda, que o fato de três professores se disponibilizarem a planejar e executar atividades de classe que permitissem trocas entre alunos e nos possibilitarem realizar as observações em suas turmas, colaborou efetivamente com nossa investigação, ou seja, que a abertura para nossa observação em sala de aula e a preocupação desses professores com a escolha de tarefas que favoreciam o trabalho conjunto dos estudantes na resolução de problemas também revelou um dos aspectos que caracterizam a positividade dos resultados obtidos em decorrência da intervenção do grupo de pesquisa na escola, com a realização das oficinas.

Outro aspecto dessa intervenção que consideramos positivo deu-se no momento de retorno, no qual realizamos nova oficina, apresentando as videogravações ocorridas na própria instituição de ensino. Este foi também um espaço rico de discussões, principalmente porque os professores se sentiram contribuindo com a pesquisa. Ao visualizarem as imagens e observarem os diálogos das crianças nas filmagens, compreendiam o que estávamos identificando como estratégias de mediação, considerando as três categorias definidas por nós, e, inclusive, indicaram outras estratégias que acrescentamos quando retomamos as análises comparativas com os achados na outra escola.

Assim, o ciclo de oficinas realizado com os professores contribuiu para suscitar reflexões acerca das propostas de trabalho colaborativo, envolvendo pelo menos dois alunos no contexto de sala de aula. As discussões embasadas pelos estudos vygotskyanos propiciaram uma maior compreensão e sensibilização dos integrantes dessas oficinas, no tocante às possibilidades de construção de conhecimento e aprendizagem decorrentes das situações interativas entre crianças. Ademais, para os três professores que prosseguiram conosco na investigação nos momentos em que estivemos em suas salas de aula, tornou-se relevante a compreensão de que tarefas desempenhadas em conjunto pelos alunos, nas condições de compartilhamento de problemáticas e das respectivas estratégias montadas para lidar com elas, constituíam importantes espaços de trocas simbólicas e de situação de ensino-aprendizagem.

\section{AS INTERAÇÕES ENTRE OS ESTUDANTES E SUAS ESTRATÉGIAS DE MEDIAÇÃO}

Nas situações de ensino-aprendizagem que acontecem no espaço escolar, espera-se que a intervenção do professor tenha um caráter mediador, enquanto alguém que dispõe de ferramentas (conhecimentos e técnicas) capazes de favorecer a construção de conhecimentos dos seus alunos. Neste aspecto, podemos dizer que os professores utilizam estratégias didático-pedagógicas com a intenção de favorecer novas aprendizagens e, por conseguinte - de acordo com a perspectiva de Vygotsky (2001) promover processos de desenvolvimento.

Discussões realizadas por vários autores a partir de estudos sobre interações entre crianças (Cazden, 1991; Rogoff, 1993; Tudge, 1996; Loos, 2004; Colomina \& Onrubia, 2004, Werlang, Schneider \& Silveira, 2008) têm indicado que essas interações, seja no ambiente escolar seja fora dele, propiciam situações de aprendizagem e de construção conjunta de conhecimentos. Nossa preocupação nesta investigação, como já afirmamos antes, era focalizar as interações entre as crianças e buscar identificar e compreender as estratégias utilizadas por elas quando compartilhavam a realização de tarefas e resolução dos problemas escolares apresentados pelo professor.

Nossas observações, tanto na primeira etapa da pesquisa (nas turmas da escola particular) como nessa segunta etapa, reafirmaram a potencialidade das interações entre os alunos. Nas análises que realizamos para identificação das estratégias, percebemos que a natureza da tarefa influenciava na escolha das estratégias a serem usadas - por exemplo, o uso da contagem manual como estratégia na resolução de tarefas matemáticas ou o uso de sons das palavras ou a silabação nas tarefas de linguagem. Por outro lado, algumas estratégias eram recorrentes em tarefas de conteúdos distintos, como a repetição da fala do outro, a complementaridade de leitura ou de ideias e outras. Desse modo, categorizamos as diversas estratégias identificadas seguindo o critério do tipo de tarefa que ela mediava. Essas estratégias foram então organizadas em três tipos: estratégias empregadas na resolução de tarefas de matemática, estratégias empregadas na resolução de tarefas de linguagem e estratégias gerais, quando recorrentes nos dois tipos de tarefa. 
De forma esquemática, os tipos de estratégia encontrados a partir dessa categorização escolhida foram estratégias gerais, estratégias de tarefas de linguagem e estratégias de tarefas de matemática.

- As ESTRATÉGIAS GERAIS comprenderam: complementaridade de leitura e de ideias; repetição da fala do outro; diferentes tipos de negociação de sentidos/significados, de modo de resolução da tarefa, da interpretação do enunciado, etc.; oralização, envolvendo leitura alta para compreensão da tarefa; destaque, com sublinhamento ou entonação forte, de palavras e/ou frases, etc.; e gesticulações como apontar, bater na mesa, desenhar no ar.

- As ESTRATÉGIAS DE TAREFAS DE LINGUAGEM consistiram de: silabação/soletração; generalização de conceitos; uso de relações de proximidade sonora entre palavras; sonorização; exemplificação para ilustrar a compreensão da tarefa.

- As ESTRATÉgIAS DE TAREFAS DE MATEMÁTICA consistiram de contagem com os dedos e/ou visualização da configuração dos dedos para os cálculos; representações numéricas de diversas formas, como marcas, desenhos, etc.; decomposição de cálculos complexos em pequenos cálculos simples; uso da lógica prescindindo do cálculo; uso de operações inversas; uso dos algoritmos relativos às operações matemáticas; aproveitamento de parte de um cálculo realizado para outro problema e; conferência/correção dos cálculos parciais.

Algumas das estratégias acima mencionadas podem ser exemplificadas a partir de excertos encontrados nas transcrições das atividades. No caso das quatro crianças da alfabetização, ao realizarem um exercício de formação de palavras, ilustramos a estratégia categorizada como silabação, na qual uma das meninas (Amanda) repetia as sílabas a fim de apreender a escrita da palavra, enquanto a outra silabava durante sua escrita, bem como indicava para a colega essa escrita através da silabação.

\section{Excerto n* 1}

Profa.: (indicando no quadro a palavra escrita xícara) E essa?

Carlos $^{4}$ : xícara

Profa.: $\quad x i ́(. .$.

4 Todos os nomes utilizados são fictícios para preservar as identidades das crianças envolvidas.
Turma: cará

Profa.: ótimo! Muito bem!

Carlos: xiiiiii (silaba enquanto escreve)

Amanda: $x i ́-c a-r a ; x i-c a-r a ́$. (repete a silabação antes de escrever)

Lena: eu não sei não como é.

Carlos: $x i ; x i$ - ca; xicará (silabando de modo enfático para a colega). Entendeu, oh!

Lena: siiiim.

Nas atividades de linguagem com alunos de quarta série também identificamos diversas estratégias de mediação, das quais o excerto abaixo é ilustrativo, marcando os processos dialógicos de construção de conhecimento e de subjetividade em curso.

\section{Excerto n. ${ }^{\circ} 2$}

Larissa: Ó, vou ler até aqui (marca no seu texto). Vou ler até aqui (Marca no texto de Joana) (ênfase)

Joana: Urso.

Larissa: Bota lá (vira a página do caderno de Joana)

Joana: Eu sei! Aqui.

Larissa: Passeavam dois amigos na floresta, quando apareceu um urso feroz e lançou sobre eles. Um deles trepou a árvore (...) um deles trepou a árvore e escondeu-se, enquanto o (...)

Joana: $\quad$ o outro (...) (complementaridade da leitura)

Larissa: Ficava no chão.

Joana: O outro. (risos).

Larissa: O outro ficava no (...) ficava no caminho. Deixando-se cair ao solo fingiu-se de morto. $O$ urso aproximou-se e cheirou o homem, mas este, este retinha a respiração, julgou-o morto e afastou-se. (repetição e complentaridade de leitura)

Joana: Um dos amigos subiu na árvore. O que fez o outro? (Segunda questão). Fingiu-se de morto.

Larissa: Não! É não, ó (e aponta para o texto em seu caderno).

Joana: $\quad$ É isso aqui (apontando para o caderno de Larissa).

Larissa: Espera ainda (e lê o texto). Enquanto o outro ficava no caminho. (olha para Joana).

Joana: Fingiu-se de mor-to! (Apontando para o caderno de Larissa). 
Larissa: Sim, mas ó, um deles trepou a árvore.

Joana: Olha a pergunta! (e lê). Um dos amigos subiu na árvore. O que o outro fez? O que fez o outro?

Larissa: É, ó, Enquanto o outro ficou no caminho, né não?

Joana: Esse aqui num subiu na árvore? Esse se fingiu de morto! (aponta para o desenho do texto do caderno de Larissa)

Larissa: Foi, mas aqui ele subiu na árvore. Ó, ele vai subir na, escondeu-se, ó (circulando a palavra "escondeu-se" em seu próprio texto.) (...) na árvore, aqui ó. (ênfase circula a palavra - para negociar a interpretação e resposta da questão)

Joana: Vou botar essa mesmo.

Larissa: Pois depois vambora perguntar a professora pra ver se tá certo. Faça primeiro. Faça o que você disse.

A postura de Larissa evidencia que, na interação entre pares nos processos de ensino e aprendizagem, não só conteúdos são internalizados pelas crianças, mas nestes um processo dialógico e mediado semioticamente de construção compartilhada de conhecimento e subjetividade tem potencial para ocorrer, afirmando processos de formação $\mathrm{e}$ desenvolvimento humano. A garota por vezes orienta a colega, dividindo as atividades na resolução da tarefa, circulando palavras no texto na busca de evidenciá-las, apoiando-se nas questões e trechos do livro, entre outras estratégias. A dupla repete e confere as respostas e leituras das questões e trechos do texto em diferentes entonações, como forma de buscar esclarecimento e respaldo para as suas interpretações dos enunciados, indicando recorrer ainda à figura/papel social da professora como forma de legitimação de um saber correto e de autoridade saberes que estão presentes não só na fala ou no lugar social do professor, mas também no conteúdo e nos valores simbólicos do livro didático, demostrando os processos dialógicos e polifônicos que se materializam na linguagem, como nos indica Bakhtin (1988).

Conforme explicamos, as estratégias são modos de operar com os problemas para facilitar a sua resolução. Neste sentido, as crianças buscam os mais diferentes recursos que lhes possibilitam lidar com as tarefas que os professores lhes propõem. Tais estratégias não são exclusivas das situações de interação, pois também individualmente estes métodos são usados. A diferença é que nas interações eles são explicitados para o outro e com isso atuam como mediadores intersubjetivos e ao mesmo tempo reorganizam o pensamento e promovem novas construções e novas aprendizagens.

Outra peculiaridade que encontramos nas análises é que algumas estratégias envolvem instrumentos e outras são predominantemente simbólicas. Essa modalidade de categorização não obedece às fronteiras do tipo de atividade. Foi observado o uso de instrumentos em tarefas de linguagem - por exemplo, sublinhar para marcar as sílabas das palavras - e em tarefas de matemática - como, por exemplo, contagem manual. Já no plano meramente simbólico identificamos, por exemplo, a generalização de conceitos nas tarefas de linguagem e o uso da lógica do problema, que dispensava a realização do cálculo aritmético em tarefas de matemática.

Outro exemplo que podemos destacar refere-se aos alunos da sexta série na resolução de uma atividade de matemática. A tarefa envolvia um problema para ser calculado pela regra de três. $\mathrm{O}$ excerto abaixo mostra a parte final da resolução do problema em que Mauro explica para Fabiana seu raciocínio.

\section{Excerto n. ${ }^{0} 3$}

Fabiana: Tem certeza que é duas colheres por quê? Por que duas colheres?

Mauro: Tem que fazer do mesmo jeito.

Mauro: Duas vezes 1500, quanto é? É um litro e meio.

Fabiana: Duas vezes mil e quinhentos é trezentos.

Mauro: Trezentos? Não é três mil não?

Fabiana: $O h$ ! (ri, percebendo seu erro)

Mauro: É três litros de água. Aí, ó, dá 3.000, aí deixa sempre o x aqui. Aí vem o 200.

Fabiana: Repete tudo.

Mauro: (seguindo o cálculo) Aí corta, corta, corta e corta (risca os algarismos que vão sendo eliminados). Aí agora tem que somar, ó, 30 duas vezes.

Mauro: Dá quanto, ó...

Mauro: Fabiana, dá quinze, Fabiana, dá quinze.

Fabiana: Não dá (balançando enfaticamente a cabeça).

Mauro: Faz de conta que aqui é o 60,10, 10 e 10 (representa com marcas os números que vai contando).

Fabiana: Aí ó 10 e 10 (pegando o lápis do colega e reforçando as marcas feitas por ele representativas das dezenas). 
Mauro: Dividir para duas pessoas ó. Dá cinco... (retomando as marcas da colega).

Fabiana: E aí parte essa aqui no meio que é cinco pra cada (faz as contas riscando tracinhos indicativos de dezena no caderno).

Compreendemos que o emprego de estratégias adequadas para determinados tipos de tarefa, como o uso dos dedos ou marcas para auxiliar na contagem, pode ser visto como um indício do percurso de internalização do mediador simbólico - no caso, a contagem numérica. Isso pode ser reforçado com a análise de eventos em que a contagem foi feita ou de modo mental ou apenas com a pronúncia dos números em voz baixa, estratégia observada mais comumente na turma de sexta série.

Esta diferenciação pode indicar que o processo de internalização se evidencia com maior clareza nos alunos da sexta série em relação aos da quarta série e aos da alfabetização; entretanto, esta conclusão dependeria de outras análises que ainda não realizamos.

No que se refere ao estudo comparativo que fizemos entre os resultados das duas etapas do projeto de pesquisa, não foram identificadas diferenças significativas entre as estratégias utilizadas pelas crianças da escola particular e da escola filantrópica, com a ressalva de que, na primeira, apenas turmas de quarta-série foram investigadas. As diferenças apareceram, na segunda escola, entre as séries (alfabetização, quarta-série e sexta-série), ou seja, parecem mais vinculadas ao processo de desenvolvimento das crianças, como podem indicar as ideias mencionadas no parágrafo anterior; mas para tal conclusão requerem-se novas análises. O que podemos interpretar deste resultado é que a didática utilizada pelo professor em sala de aula tem um papel importante no favorecimento de situações que possibilitam aos alunos discutir e criar estratégias para a resolução das tarefas escolares. Assim, apesar de as escolas terem propostas pedagógicas diferentes, a criação de um espaço em que as interações entre os alunos aconteçam potencializa a construção de estratégias compartilhadas de mediação, que, por sua vez, favorecem o aprendizado em sala de aula.

As investigações realizadas nas duas escolas reforçam e reafirmam as conclusões de que, não apenas na mediação oportunizada nas relações entre o professor e seus alunos, mas também nas interações entre os alunos, identificam-se emergências de zonas de desenvolvimento proximal (Vygotsky, 2001), entendidas como espaço simbólico de construção compartilhada (Meira \& Lerman, 2001), e, neste sentido, as interações entre pares exercem um papel desencadeador de aprendizagens e de consolidação do desenvolvimento psicológico das crianças.

\section{TECENDO ALGUMAS CONSIDERAÇÕES}

A intenção que moveu o grupo de pesquisa a adentrar o cotidiano escolar com o propósito de investigar a maneira como as crianças criam e empregam estratégias para lidar com as tarefas escolares e constroem conhecimentos nesse processo pautou-se na crença de que os achados daí decorrentes poderiam contribuir para ampliar as discussões acerca de intervenções pedagógicas baseadas em interações entre estudantes. Neste aspecto, consideramos que os resultados da pesquisa trouxeram contribuições, particularmente, no que diz respeito à compreensão dos aspectos mediacionais para a construção do conhecimento compartilhado. Destarte, este estudo situa-se na continuação de muitos outros, corroborando a investigação das peculiaridades das estratégias que são criadas em contextos de sala de aula e entre crianças de realidades diversas, convidando-nos não só a perceber e fomentar processos individuais, mas também a focar as potencialidades constitutivas da colaboração com o outro e usar as ferramentas culturais nos contextos e processos histórico-culturais e singulares nas interações e atividades significadas e partilhadas coletivamente.

Coerente com o referencial usado, a proposta de intervenção como parte integrante do processo de pesquisa também mostrou-se significativa. Nas oficinas iniciais a pesquisa foi aperfeiçoada a partir da realidade da escola em estudo. Com isso, percebemos o avanço em relação às pesquisas anteriores realizadas pelo grupo, na medida em que criamos um espaço para a intervenção junto aos docentes e consideramos peculiariades próprias da escola, isto é, seu contexto social, modos de atuação pedagógica e relações estabelecidas entre professores e alunos e destes entre si.

Compreendemos que as similaridades das estratégias encontradas nas duas investigações reforçam a compreensão do papel mediador do professor quando este promove situações de interação entre os estudantes que, por sua vez, favorecem a emergência de zona de desenvolvimento proximal.

Ao buscar elucidar as estratégias de mediação, intentamos compreender os processos psíquicos envolvidos na atividade pedagógica produtora de conhecimento, identificar as lógicas subjacentes aos modos de resolução compartilhada e, a partir daí, inferir situações outras de ensino/aprendizagem. 
Com base nessas diretivas, procuramos entender o pensamento infantil em atividade, não como um pensamento faltante, se comparado com o do adulto, mas como um pensamento com suas especificidades, que são melhor entendidas em sua dimensão microgenética.

Assim, para vislumbrarmos o fenômeno psíquico adentramos nas zonas de sentido que emergiram em função das interações verbais e não verbais. Do ponto de vista da linguagem, as enunciações são significativas e denunciadoras de possíveis significados dados à palavra, o que compreendem Vygotsky e Bakhtin como algo que nos dá acesso à consciência humana.

A partir dessas considerações, cremos que estudos que enfocam o cotidiano escolar auxiliam na reflexão sobre projetos pedagógicos, capacitação do corpo docente e abertura para novas práticas, além do incentivo a novos campos de investigação. Destarte, ao entendermos a educação como uma área estratégica na trama social que, baseada no compromisso daqueles que se encontram no espaço escolar, pode promover transformações no contexto mais amplo da sociedade, também estamos nos envolvendo com esse compromisso.

\section{REFERÊNCIAS}

Bakhtin, M. V. (1988). Marxismo e Filosofia da Linguagem. $4^{\mathrm{a}}$ ed. São Paulo: Hucitec.

Cazden, C. B. (1991). El discurso en el aula. El lenguaje de la enseñanza y del aprendizaje. Barcelona: Paidós.

Colaço, V. F. R. (2001). Interações em sala de aula: um estudo da atividade discursiva de crianças em séries iniciais. Tese de Doutorado Não-Publicada. Programa de Pó-Graduação em Educação. Universidade Federal do Rio Grande do Sul, Porto Alegre.

Colaço, V. F. R.; Pereira, E.; Chaves, H. V.; Pereira Neto, F. E. \& Sá, T. S. (2007). Estratégias de mediação em situação de interação entre crianças em sala de aula. Estudos de Psicologia. 1(12), 4756. Recuperado em 20 de abril de 2008 de http://www.scielo.br.

Coll, C. \& Onrubia, J. (1998). A construção de significados compartilhados em sala de aula: atividade conjunta e dispositivos semióticos no controle e no acompanhamento mútuo entre professor e alunos. Em C. Coll, \& D. Edwards, (Orgs.). Ensino, Aprendizagem e discurso em sala de aula: aproximações ao estudo do discurso educacional (pp. 75-106). Porto Alegre: Artmed.

Colomina, R. \& Onrubia, J. (2004, $2^{\text {a }}$ ed.). Interação educacional e aprendizagem escolar: a interação entre alunos. Em C. Coll; J.
Palacios \& A. Marchesi. Desenvolvimento psicológico $e$ educação: Psicologia da educação escolar. (Vol. 2) (pp. 280-293). Madrid: Alianza Editorial.

Freitas, M. T. A. (2003). A perspectiva sócio-histórica: uma visão humana da construção do conhecimento. Em M. T. Freitas; S. J. Souza \& S. Kramer (Orgs.). Ciências Humanas e pesquisa: leituras de Mikhail Bakhtin. São Paulo: Cortez.

Góes, M. C. R. de (2000). A abordagem microgenética na matriz Histórico-Cultural: uma perspectiva para o estudo da constituição da subjetividade. Cadernos CEDES. Campinas, 50(20), 9-25.

Loos, H. (2004) Ansiedade e aprendizagem: um estudo com díades resolvendo problemas algébricos. Estudos de Psicologia. 3

(9), 563-573. Recuperado em 10 de outubro de 2008 de http://www.scielo.br.

Meira, L. R. L. \& Lerman, S. (2001). The Zone of Proximal Development as a symbolic space. Social Science Research Papers, Londres, UK, 13 (1), 1-40.

Tudge, J. (1996). Vygotsky, a zona de desenvolvimento proximal e a colaboração entre pares: implicações pedagógicas para a prática em sala de aula. Em L. C. Moll. Vygotsky e a educação: implicações pedagógicas da psicologia sócio-histórica (pp. 156174). Porto Alegre: Artes Médicas.

Oliveira, M. K. (1996). Lev Vygotsky. São Paulo: ATTA Mídia e Educação: São Paulo. (DVD).

Oliveira, M. K. (2005). História, consciência e educação. Viver Mente e Cérebro - Coleção Memória da Pedagogia, São Paulo, 2, 6-13.

Rogoff. B. (1993). Interacción entre iguales y desarrollo cognitivo. In B. Rogoff. Aprendices del pensamiento: el desarrollo cognitivo en el contexto social (pp. 219-240). Barcelona: Paidós.

Vygotsky, L. S. (1993). Obras Escogidas, Pensamiento y Lenguaje. Conferencias sobre Psicología. Tomo II. Madrid: Visor.

Vygotsky, L. S. (1995). Obras Escogidas, Problemas del desarrollo de la psique. Tomo III. Madrid: Visor.

Vygotsky, L. S. (2001). Psicologia pedagógica. São Paulo: Martins Fontes.

Werlang, R. B.; Schneider, R. S. \& Silveira, F. L. (2008). Uma experiência de ensino de física de fluidos com o uso de novas tecnologias. Revista Brasileira de Ensino de Física. 1(30), 1503.1-1503.9. Recuperado em 10 de outubro de 2008 de http://www.scielo.br.

Wertsch, J. (1998). A necessidade da ação na pesquisa sociocultural. Em J. Wertsch; P. Río; A. Alavarez (Orgs.). Estudos socioculturais da mente. Porto Alegre: Artmed.

Recebido em 04/03/2009 Aceito em 16/12/2009

Endereço para correspondência : Veriana de Fátima Rodrigues Colaço. Departamento de Psicologia da UFC. Av. da Universidade, 2762, Bairro Benfica, CEP 6002-180, Fortaleza-CE, Brasil. E-mail: verianac@uol.com.br 
